\title{
Bazı Balık Türlerinde Yapılmış Transgenik Çalışmalar
}

\section{Semra KüçüK ${ }^{* 1}$ (i)}

\section{${ }^{1}$ Aydın Adnan Menderes Üniversitesi Ziraat Fakültesi Su Ürünleri Mühendisliği Bölümü, Güney Kampüsü 09100 Aydın}

Öz: İnsanlığı, gelecek yıllarda tehdit edecek faktörlerden biri de "gıda kıtlığı" olacağı çok açıktır. Bu nedenle gıda konusunda bir devrim yapan biyoteknolojik gelişmelerin bu kıtlığın önüne geçeceği düşünülmektedir. Bu gelişmeler tüm tarım ürünlerinde gerçekleştiği gibi su ürünlerinde de yerini almıştır. Bu çalışma da, su canlılarının hangi türlerinde gen aktarımı olduğu, bu konuda hangi yöntemler kullanıldığı ve transgenik su ürünlerinin insanı ve doğayı etkileyecek fayda ve risklerinin neler olduğuna yer verilmiştir.

Anahtar Kelimeler: transgenik, su ürünleri, gen aktarımı

\section{Transgenic Studies on Some Fish Species}

Abstract: In the future, scarity of food will be one of the factors that threaten the humanity. Well, It is thought that biotechnological developments will prevent this lack. These developments happen in aquatic products as all of the agriculture products. In this study, it is discussed which species of aquatic organisms gen transfer were done on, which methods it is used and what are the avantages and disavantages of transgenic aquatic products that affect human and nature.

Keywords: transgenic, aquatic products, gen transfer

\section{GíRiş}

DNA'nın çift sarmal yapıda olduğunun 1953 yılında Watson ve Crick tarafından keşfedilmesi ile gen teknolojisinin ilk adımları atılmıştır. Her hücrenin çekirdek yapısının DNA'dan meydana gelmesi hücreler arası DNA değişimini olası kılmıştır. İlk gen aktarımı farelerde mikroenjeksiyon yöntemiyle Gordon ve arkadaşları tarafından 1980 yılında gerçekleştirilmiştir. Balıklarda ilk gen transferi ise Zhu ve arkadaşları tarafından 1985 yılında japon balıkları (Carassius auratus) yumurtaları üzerinde yapılmıştır. Gen teknolojisi yaklaşık 40 yıldan beri tıp, veterinerlik, tarım başta olmak üzere ormancılık, çevre, enerji ve kozmetik alanında etkin şekilde kullanılmaktadır. Ülkemizde ilk gen transferi fareler üzerinde TÜBITAK-MAM Gen Mühendisliği ve Biyoteknoloji Enstitüsü’nde 1993 yılında yapılmıştır (Bağış, 1980). Dünya da Sazan (Cyprinus carpio), kanal yayını (Ictalurus punctatus), Japon balığı (Carassius auratus), medaka (Oryzias lapites), zebra balığı (Danio rerio), gökkuşağı alabalığı (Oncorhynchus mykiss), tilapia (Oreochromis niloticus), Atlantik salmonu (Salmo salar), istiridye (Mulinia lateralis), alg (Spirulina platensis) ve istakoz (Procambarus clarkii) gibi su canlılarında gen transferi yapılmıştır (Ekici ve ark., 20 06; Akhan ve Canyurt, 2008; Özdemir ve ark., 2008). Su ürünlerinde gen transferi yapılmış türler Çizelge 1 'de verilmiştir.

Verilen 2016 istatistiklere göre dünya su ürünleri üretimi 171 milyon tondur. Bunun 81 milyon tonu yetiştiricilik, 90 milyon tonu maksimum seviyeye ulaşmış avcılık üretimidir (Anonim, 2019). Su ürünleri üretiminde son 30 yıla göre artış yetiştiricilik yoluyla sağlanmıştır. Gelecekte üretim artışı türler üzerinde yapılacak seleksiyon ve gen transferi uygulamaları ile sağlanabilecektir. Bu konular üzerinde yapılan çalışmalar son 20 yılda önemli bir hız kazanmıştır. Balıklarda gen transferi üzerine yapılan çalışmalarda hızı büyüme, soğuğa dayanıklılık, hastalıklara karşı direncin artırılması ve üreme kontrolü gibi konular araştırılmıştır (Akhan ve Canyurt, 2008).

GEN TRANSFERI KONUSUNDA SU ÜRÜNLERINDE YAPILMIŞ ÇALIŞMALAR

\section{Hızlı Büyüme}

Canlılarda transgenik yöntemlerle hızlı büyüme çalışmaları ilk olarak fareler üzerinde 1982 yılında Palmiter tarafından yapılmıştır. Sonrasında insan büyüme hormonu geni (hGH) japon balıklarına (Zhu ve ark., 1985) ve Misgurus anguillicaudatus balıklarına (Zhu ve ark., 1986) aktarılması çalışmaları yapılarak ilk hızlı büyüyen transgenik balıklar elde edilmiştir. Bunun ardından balık büyüme hormonu geni $(\mathrm{GH})$ transferi ilk kez sazan balıklarında denenmiştir (Zhu, 1992; Wang ve ark., 2001). Sonrasında, Chinook salmon (Oncorhynchus tshawytscha) büyüme geni aktarılmış Nil tilapia balıklarında ( $O$. niloticus) normallerine göre canlı ağırlık artışı, spesifik büyüme oranı daha fazla ve yem değerlendirme katsayısı daha düşük çıkmıştır (Rahman ve ark., 1998). Büyüme hormonu aktarılmış transgenik coho salmon balıklarının (Oncorhynchus kitsutch) transgenik olmayanlarına göre yem yakalama ve tüketme miktarlarının daha yüksek olduğu bildirilmiştir (Devlin ve ark., 1999). Aynı

Sorumlu Yazar: skucuk@adu.edu.tr Bu makale 1-4 Kasım 2018 tarihleri arasında Aydın Kuşadası'nda düzenlenen Uluslararasi Genomik ve Biyoinformatik Konferansında Poster bildiri olarak sunulmuş ve özeti bildiri kitapcığında basılmıştır.

Geliş Tarihi: 16 Aralık 2018

Kabul Tarihi: 24 Haziran 2019 
Çizelge 1. Su canlılarında ilk gen transferi yapılmış türler

\begin{tabular}{|c|c|}
\hline Tür & Hedef Değişim \\
\hline $\begin{array}{l}\text { Kanal Yayını } \\
\text { (Ichtalurus punctatus) }\end{array}$ & Bakteriyel rezistans \\
\hline $\begin{array}{l}\text { Japon balığı } \\
\text { (Carassius auratus) }\end{array}$ & \\
\hline $\begin{array}{l}\text { Medaka } \\
\text { (Oryzias lapites) }\end{array}$ & Mutasyon belirleme \\
\hline $\begin{array}{l}\text { Zebra balığı } \\
\text { (Danio rerio) }\end{array}$ & $\begin{array}{l}\text { Kırmızı veya yeşil floresan renk } \\
\text { oluşturma }\end{array}$ \\
\hline $\begin{array}{l}\text { G. alabalı̆̆ı } \\
\text { (Oncorhynchus mykiss) }\end{array}$ & $\begin{array}{l}\text { Karbohidrat metabolizmasında } \\
\text { iyileşme }\end{array}$ \\
\hline $\begin{array}{l}\text { Tilapia } \\
\text { (Oreochromis niloticus) }\end{array}$ & Pıhtılaşma faktörü üretimi \\
\hline $\begin{array}{l}\text { Atlantik salmonu } \\
\text { (Salmo salar) }\end{array}$ & $\begin{array}{l}\text { Büyüme oranında artış, yem } \\
\text { alımında iyileşme }\end{array}$ \\
\hline $\begin{array}{l}\text { Loach balığı } \\
\text { (Misgurnus mizolepis) }\end{array}$ & $\begin{array}{l}\text { Yem değerlendirme katsayısının } \\
\text { düşürülmesi, sterilite (kısırlık) }\end{array}$ \\
\hline $\begin{array}{l}\text { İstiridye } \\
\text { (Mulinia lateralis) }\end{array}$ & Bakteriyel rezistans \\
\hline $\begin{array}{l}\text { Alg } \\
\text { (Sipurilina.platensis) }\end{array}$ & I değeri arttırma \\
\hline $\begin{array}{l}\text { İstakoz } \\
\text { (Procambarus clarkii) }\end{array}$ & $\begin{array}{l}\text { Transgenik yumurta } \\
\text { Üretimi }\end{array}$ \\
\hline
\end{tabular}

şekilde yine büyüme hormonu geni aktarılmış Nil tilapia balıklarının (O. niloticus) normallerine göre uzun dönem yetiştiricilikte (7 ay) 2-5 kez daha fazla büyüdükleri, ayrıca toplam boy uzunluğunun, iç organ-somatik indeksin, hepato-somatik indeksin daha yüksek, gonado-somatik indeksin daha düşük ve yem değerlendirme katsayısının daha etkin olduğunu ve kısa dönem yetiştiricilikte (4 hafta) ise transgenik tilapiaların normallerine göre 4 kez daha hızlı büyüdüklerini ve yemdeki proteini ve enerjiyi daha etkin kullandıkları bildirilmiştir (Rahman ve ark., 2001). Tilapia balığı büyüme hormonu geni aktarıımış sazan balıkları ( $C$. carpio) normallerine göre 1.49 kat daha fazla ağırlık kazanmışlardır. Aynı zamanda bu transgenik sazanların normallerine göre yaşama oranı daha iyi, spesifik büyüme oranı daha yüksek, yem tüketimi daha fazla, yem değerlendirme katsayısı daha düşük ve suya amonyak salınımları daha düşük bulunmuştur (Alimuddin ve ark., 2016).

\section{Hastalıklara Dayanıklılık}

Su ürünleri yetiştiriciliğinde bakterial, viral ve paraziter hastalıklardan korunmak önemli bir konudur. Zira bu hastalıklar önemli derecede ekonomik kayıplara neden olmaktadır. Günümüzde balık hastalıklarından korunmak amaçı antibiyotikler ve aşılar kullanılmaktadır. Fakat geçen zaman içinde patojenik mikroorganizmalar antibiyotiğe karşı dayanıkııık kazanmaya başlamıştır ve balık hastalıklarının kontrolünde sorunlar yaşanmaktadır. Aşılara bakacak olursak bir seri hastalık için aşı geliştirilmesi yıllar

Aktarılan Gen

Böcek geni

Kaynak

Neomisin direnç geni

Zhu ve ark., 1985

Bakteri geni

Winn ve ark., 2001

Pigment geni

Gong ve ark., 2003

Glikoz Tip I

Hekzokinaz Tip II

Pitkanen ve ark., 1999

Insan geni

Hallerman, 2003

Büyüme hormonu

Zhang ve ark., 1990

Büyüme hormonu

Retroviral vektör geni

Metallotionein

Retroviral vektör geninin ebeveyn gonadlarına enjeksiyonu

sürmüştür. Yeni bir aşının geliştirilmesi için çok fazla para, zaman ve iş-güçü sarf etmek gerekmektedir. Ayrıca bir aşı uygulaması için de çok iş-gücü ve zaman ayırmak zorunluluğu vardır. Bu nedenle gen aktarımı ile balıklarda hastalıklara karşı direnç oluşturulması çok talep görecek bir işlem olacaktır.

Böceklerden memelilere kadar birçok hayvanda bulunan cecropinler veya buna benzer antimikrobiyal peptidler bulunmaktadır. Cecropinler doğal kaynaklardan veya kimyasal olarak oluşturulan sentetikleri birçok çalışmada kullanılmaktadır. Bir güveden (Hyalophora cecropia) cecropin B veya CF 17 (sentetik analog) genlerini Japon medaka balığına (O. latipes) aktarılarak birçok önemli balık virüs patojenlerine (İnfeksiyöz Hematopoietik Nekroz Virüsü- IHNV, Viral Hemorajik Septisemi Virüsü-VHSV, Yılanbaşı Rapdovirüsü-SHRV, İnfeksiyöz Pankreatik Nekroz Virüsü-IPNV) karşı bir korumanın oluşup oluşmadığı araştırılmıştır. Sonuç olarak balık hücrelerindeki patojen virüs sayısında önemli derecede (104 kat) azalmanın olduğu gösterilmiştir (Chiou ve ark., 2002).

Ot sazanlarının ölümcül bir hastalığı olan Hemorajik Septisemiden $(\mathrm{GCH})$ korunmak amaçlı ot sazanlarına insan lactoferrin geni elektroporasyon yöntemi ile aktarılmıştır. Sonuçta, ot sazanlarında başarılı bir koruma sağlandığı bildirilmiştir.(Zhong ve ark., 2002). Antimikrobiyal aktivite sağlayan 4 farklı cecropin B (preprocecropin B, procecropin $B$, cecropin B ve porcine P1 cecropin) güve geni Chinook salmon embriyo hücre kültürüne (CHSE-214) aktarılmıştır. 
Sonuçta da, bu hücre kültürünün Aeromonas hydrophila, Pseudomonas fluorescens ve Vibrio anguillarum karşı bakterisidal etkiye sahip olduğu rapor edilmişdir (Sarmasik ve Chen, 2003).

Cecropin B geni kanal yayını balıklarına (I. punctatus) aktarılmış evebeynlerden (P1) elde edilen F1 döllerinin toprak havuzlarda Columnaris hastalığı etkeni olan Flavobacterium columnare patojenine karşı dayanıklılıkları araştırılmış ve transgenik balıklarda yaşama oranı \%100 iken normal balıklarda yaşama oranı \%27.3 bulunmuştur. Ayrıca aynı tür transgenik balıkların tanklarda Kanal Yayını Enterik Septisemia Hastalığı (ESC) oluşturan Edwardsiella ictaluri patojenine karşısında yaşama oranları araştırılmıştır. Transgenik balıklarda \%40.7 ve normal balıklarda \%14.8 yaşama oranı bildirilmiştir (Dunham ve ark., 2002). Cecropin P1 veya CF-17 genleri aktarılmış transgenik gökkuşağı balıklarının (O. mykiss) da Aeromonas salmonicida bakterisine ve İnfeksiyöz Hematopoietik Nekrosiz Virisüne (IHNV) karşı yüksek bir dayanıklılık gösterdikleri bildirilmiştir (Chiou ve ark., 2014).

\section{3. Üreme Kontrolü}

Transgenik balıkların doğaya kaçarak yabani türlerle çiftleşip üremelerine engel olmak amacıyla transgenik bireyler steril yani kısır olarak üretilmektedirler. Bu durum, geleneksel yöntemler yanında gonadotropin serbestleştirici hormon $(\mathrm{GnRH})$ geni susturulan transgenik balıklarla sağlanmaktadır (Maclean ve Laight, 2000).

\section{Soğuğa Dayanıklılık}

Bazı balık türleri $0{ }^{\circ} \mathrm{C}$ ve altında yaşayabildiklerinden bu balıkların vücutlarında bazı antifriz görevi gören proteinler bulunmaktadır. İşte, bu balıkların genlerinin ekonomik değeri yüksek balıklara aktarılarak transgenik balıkların oluşturulması söz konusudur. Balıklar da başlıca 4 temel tipte antifriz proteini bulunmaktadır. Birincisi Antartika morina balığında (Dissostichus mawsoni) bulunan "glycoproteins", ikincisi kış pisi balığında (Pseudopleuronectes americanus) bulunan "Tip । antifreeze", üçüncüsü iskorpit balığında (Hemitripterus americanus) bulunan "Tip II antifreeze" ve dördüncüsü Perciformes takımından bir balık türünde (Zoarces americanus) buluna "Tip III antifreeze"dir. Optimum olmayan sıcaklıklarda dahi hızlı gelişen ve yem alabilen bireyler oluşturmak amacıyla Tip I ve Tip III genleri farklı balık türlerine aktarılmıştır. Tip I Atlantik salmon balığına ( $S$. salar) transfer edilmiştir. Fakat etkin bir sonuç alınamamıştır. Aynı şekilde Tip III geni japon balıklarına aktarılmıştır. Ancak bu genin aktarımında başarılı sonuçlar elde edilememiştir (Maclean ve Laight, 2000).

\section{Renk Değişimi}

Deniz anasından (Aequorea victoria) alınan yeşil floresan protein geni ile yeşil renkli bir süs balığı olan zebra (Danio rerio) elde edilmektedir. Güncel olarak petshop marketlerde "Glofish" olarak görebileceğimiz transgenik fosfor yeşili renkte bu balıkların satışı görülmektedir (Rasal ve ark., 2016).

\section{GEN TRANSFERINDE KULLANILAN YÖNTEMLER}

Gen aktarımında çok çeşitli yöntemler kullanılmaktadır. Bunlar mikroenjeksiyon, elektroporasyon, spermatozoa hücreleriyle gen transferi, retroviral yolla transfer şeklinde sıralanabilir.

\section{Mikroenjeksiyon}

Fare ve koyun gibi yüksek omurgalı hayvanlarda en etkin kullanılan metottur. Bu teknikte transgen direkt olarak döllenmiş yumurtanın çekirdeği içine mikroenjeksiyon yöntemi ile aktarılmaktadır. Bu yöntem balıklarda da kullanılmaktadır. Fakat balık yumurta sayısı çok olduğundan bu yöntem çok iş-gücü ve zaman gerektiren bir iştir (Sarmaşık, 2003; Ekici ve ark., 2006).

\section{Elektroporasyon}

Elektroporasyon yöntemi de döllenmiş yumurtalara kısa bir seri elektrik akımı verilerek gen transferi yapılmaktadır. Bu işlem sırasında hücre çeperinin geçirgenlik özelliğinden yararlanılmaktadır. Yalnız yumurtanın chorion tabakasının elle ya da kimyasal olarak uzaklaştırılması bu yöntemin etkinliğini artırmaktadır. Fakat bu uzaklaştırma işlemi çok yorucu olduğu kadar yumurtaya da ekstra stres veren bir işlemdir. Balıkların yumurta sayısı çokluğu düşünüldüğünde bu yöntemin daha kısa zamanda uygulanabileceği görülmektedir. Etkin, hızlı ve kolay kullanımı nedeniyle birçok balık laboratuvarı tarafında tercih edilen bir yöntemdir (Sarmaşık, 2003, Ekici ve ark., 2006).

\section{Spermatozoa Hücreleriyle Transfer}

$\mathrm{Bu}$ yöntemde, transgenlerin spermatozoalar aracılığıyla yumurtalara aktarılması sağlanmaktadır. Bu nedenle diğerlerine göre en doğal ve en çok tercih edilen yöntemdir. Bu yöntem farelerde kullanılmakta olan bir metot olmasına rağmen memelilerde çok tercih edilen bir işlem değildir. Çünkü spermin üreme kanalı dışında yaşama süresi çok kısıtlıdır. Fakat balık spermatozoları seminal sıvısı içinde günlerce canlılığını koruyabildiğinden bu yöntem balıklarda gen transfer işleminde en çok gelecek vadeden yöntemdir (Sarmaşık, 2003).

\section{Retroviral Yolla Transfer:}

Bir tek kopyayı konakçı genomuna aktarmayı sağlayan bir yöntemdir. Bu nedenle balıklarda ve yüksek omurgalılarda başarıyla kullanılan bir yöntem olasına rağmen işlemi uzun, maliyet yüksek ve ileri teknoloji gerektirmektedir. Bu nedenlerden dolayı çok tercih edilmeyen bir yöntemdir (Sarmaşık, 2003).

\section{Gen Transferinin Yararları}

1. Balıklara büyüme hormonu aktarılarak onların daha hızlı büyümeleri sağlanmaktadır. Bu da üretim artışına sebep olmaktadır (Yoshizaki, 2001; Kulaç ve ark., 2006; Alimuddin ve ark., 2016).

2. Hızlı büyüme sonucu yem değerlendirme katsayısı yükselir ve sonuçta maliyet düşer ve ekonomik kazanç artar 
(Melamed ve ark., 2002.. Özyurt ve ark., 2005; Alimuddin ve ark., 2016).

Bazı patojenlere karşı dayanıklılık kazandırır (Chiou ve ark., 2014). Bazı biyotik ve abiyotik faktörlere karşı tahammül yeteneğini artırır (Antila ve ark., 2013; Wang ve ark., 2014) ve cinsiyet kontrolünde (Melamed ve ark., 2002) yarar sağlar.

\section{GENETiK YAPISI DEĞişTiRiLMIŞ SU CANLILARININ TAŞIDIĞI OLASI RISKLER}

Gen transferinin insan sağlığı ve biyoçeşitlilik açısından taşıdığı sakıncalar kısaca şöyle belirtilebilir (Özyurt ve ark., 2005; Özdemir ve ark., 2008; Şen ve Altınkaynak, 2014).

1. Transgenik su canlılarının genetik yapıları değiştiğinden farklı proteinler üretebilirler ve insan tüketiminde alerjik reaksiyonlara neden olabilirler.

2. Transgenik su canlılarına vektör virüslerle aktarılan genler insan vücudunda kanser gibi hastalıkları tetikleyebilir.

3. Transgenik su canlılarına aktarılmış genler insanların bağırsak florasındaki bakterilerle etkileşime girip bakterilerin spekturumunu değiştirebilirler.

Transfer balıklar yetiştirildiği çiftliklerden kaçarak yabani formlarla etkileşebilir ve mevcut doğal gen kaynakların bozulmasına neden olabilirler.

\section{SONUÇ}

Transgenik su canlılarının doğal populasyonlara kıyasla insan için tehlike oluşturup oluşturmayacağı hakkında henüz yeterli bilgi bulunmamaktadır. Özellikle insan sağlığı ve çevre riski taşıyan transfer su canlıları üzerine yeni araştırmaların yapılması ve desteklenmesi gerekmektedir.

\section{KAYNAKLAR}

Alimuddin K, Faridah N, Yoshizaki, C, Nuryati S, Setiawati M (2016) Growth, srvival, and body composition of transgenic common carp Cyprinus carpio $3^{\text {rd }}$ generation expressing tilapia growth hormone cDNA. Hayati Journal of Biosciences 23:150-154.

Akhan S, Canyurt MA (2008) Transgenetik balıklar: fayda ve riskleri. Journal of Fisheries Sciences 2(3):284-292.

Anonim (2019) Tarım ve Orman Bakanlığı Su Ürünleri İstatistikleri.

https://www.tarimorman.gov.tr/sgb/Belgeler/SagMe nuVeriler/BSGM.pdf (Erişim tarihi 02.04.2019).

Bağış H (1980) Transgenik balık. Bilim Teknik 5:66-67.

Burns JC, Chen TT (1999) Pantropic retroviral vectors for gene transfer in mollusks. Patent No. 5.969.211. United State Patent and Trandemark Office, Alexandria.

Chiou PP, Lin CM, Perez L, Chen TT (2002) Effect of cecropin $B$ and a synthetic analogue on propagation of fish viruses in vitro. Marine Biotechnology 4(3):294-302.

Chiou PP, Chen MJ, Lin C-M, Khoo J, Larson J, Holt R, Leong J-A, Thorgarrd G, Chen TT (2014) Production of homozygous transgenic rainbow trout with enhanced disease resistance. Marine Biotechnology 16:299-308.
Devlin RH, Johnsson JI, Smailus DE, Biagi CA, Jönsson E, Björnsson BTh (1999) Increased ability to compete for food by growth hormone-transgenic coho salmon Oncorhynchus kisutch (Walbaum). Aquaculture Research 30:479-482.

Dunhan RA, Warr GW, Nicols A, Duncan PL, Argue B, Middleton D, Kucuktaş $H$ (2002) Enhanced bacterial disease resistance of transgenic channel catfish, Ictalurus punctatus, possessing cecropin genes. Marine Biotechnology 4:338-344.

Ekici A, Timur M, Bağış H (2006) Transgenik canlılar ve akuakültürdeki önemi. E.Ü. Su Ürünleri Dergisi 23(1/2):211-214.

Gong Z, Wan H, Tay TL, Wang H, Chen M, Yan T (2003) Development of transgenic fish for ornamental and bioreactor by strong expression of fluorescent proteins in the skeletal muscle. Biochemical Biophysical Research Communications 308(1):58-63.

Hallerman E (2003) Status of development of transgenic aquatic animals. http://www.isb.vt.edu.

Kulaç I, Ağırdi, Y, Yakın M (2006) Sofralarımızdaki tatlı dert, Genetiği Değiştirilmiş Organizmalar ve halk sağlığına etkileri. Turkish Journal of Biochemistry 31(3):151155.

Lu J-K, Chen TT, Allen SK, Matsubara T, Burns JC (1996) Production of transgenic drawf surfclams, Mulinia lateralis, with pantropic retroviral vectors. Proceedings of the National Academy Sciences 93(8):3482-3486.

Maclean N, Laight RJ (2000) Transgenic fish: an evaluation of benefits and risks. Fish and Fisheries 1:146-172.

Melamed P, Gong ZY, Fletcher GL, Hew CL (2002) The potential impact of modern biotechnology on fish. Aquaculture 204: 255-269.

Nam YK, Noh JK, Cho HJ, Cho K-N, Kim CG, Kim DS (2001) Dramatically accelerated growth and extraordinary gigantism of transgenic mud loach Misgurnus mizolepis. Transgenic Research 10:353-362.

Özdemir N, Aksakal E, Alak G, Çiltaş A, Erdoğan O (2008) Su ürünleri yetiştiriciliğinde genetik modifikasyon ve insan sağığı açısından önemi. Türkiye 10. Gıda Kongresi, 21-23 Mayıs 2008, Erzurum.

Özyurt MS, Dayıoğlu H, Solak CN (2005) Gen teknolojileri ve insan hayatına etkileri. Dumlupınar Üniversitesi Fen Bilimleri Enstitüsü Dergisi 8:127-136.

Pitkanen TI, Krasnov A, Reinisalo M, Molsa H (1999) Transfer and expression of glucose transporter and hexokinasegenes in salmonid fish. Aquaculture 173:319-332.

Rahman MA, Mak R, Ayad H, Smith A, Maclean N (1998) Expression of novel piscine growth hormone gene results in growth enchancement in transgenic tilapia (Oreochromis niloticus). Transgenic Research 7: 357369.

Rahman MA, Ronyal A, Engidaw BZ, Jauncey K, Hwang G-L, Smith A, Roderick E, Penman D, Varad L, Maclean N (2001) Growth and nutritional trials on transgenic Nil 
tilapia containing an exogenous fsh growth hormone gene. Journal of Fish Biology 59:62-78.

Rasal KD, Chakrapani V, Patra SK, Ninawe AS, Sundaray JK, Jayasankar P, Barman HK (2016) Status of Transgenic Fish Production with Emphasis on Development of Food Fishes and Novel Color Varieties of Ornamental Fish: Implication and Future Perspectives. Journal of FisheriesSciences.com 10(3):52-65.

Sarmasik A, Jang I-K, Chun CZ, Lu JK, Chen TT (2001) Transgenic live-bearing fish and crustaceans produced by transforming immature gonads with replicationdefective pantropic retroviral vectors. Marine Biotechnolog 3:470-477.

Sarmaşık A, Chen T (2003) Bactericidal activity of cecropin B and cecropin P1 expressed in fish cells (CHSE-214): Application in controlling fish bacterial pathogens. Aquaculture 220(1-4):183-194.

Şen S, Altınkaynak S (2014) Genetiği değiştirilmiş gıdalar ve potansiyel sağlık riskleri. SAÜ Fen Bilimleri Dergisi 18(1):31-38.

Wang Y, Hu W, Wu G, Sun Y, Chen S, Zhang F, Zhu Z, Feng J, Zhang X (2001) Genetic analysis of "all-fish" growth hormone gene transferred carp (Cyprinus carpio L.) and its F1 generation. Chinese Science Bulletin 46:1174-1177.

Winn RN, Norris M, Muller S, Torres C, Brayer K (2001) Bacteriophage I and Plasmid pUR288 transgenic fish
KüçüK S

models for detecting in vivo mutations. Marine Biotecnology 3:185-195.

Zhang $\mathrm{P}$, Hayat $\mathrm{M}$, Joyce $\mathrm{C}$, Gonzalez-Villasenor LI, Lin CM, Dunham RA, Chen TT, Powers DA (1990) Gene transfer, expression and inheritance of pRSV-Rainbow Trout-H cDNA in the common carp Cyprinus carpio (Linnaeus). Molecular Reproducion and Development 25:3-13.

Zhang HQ, Lin AP, Sun Y, Deng YM (2001) Chemo- and radio-protective effects of polysaccharide of Spirulina platensis on hemopeietic system of mice and dogs. Acta Pharmacologica Sinica 22:1121-1124.

Zhong J, Wang Y, Zhu Z (2002) Introduction of the human lactoferrin gene into grass carp (Ctenopharyngodon idellus) to increase resistance against $\mathrm{GCH}$ virüs. Aquaculture, 214:93-101.

Zhu Z, Li G, He L, Chen S (1985) Novel gene transfer into the fertilized eggs of gold fish (Carassius auratus L. 1758). Zeitschrift für Agewandte Ichthyologie 1:31-34.

Zhu Z, Xu K, Li G, Xie Y, He L (1986) Biological effects of human growth hormone gene microinjected into the fertilized eggs of loach, Misgurus anguillicaudatus (Cantor). Kexue Tongbao 31:988-990.

Zhu Z (1992) Generation of fast growing transgenic fish: methods and mechanisms. Transgenic fish. World Scientific Publishing, Singapore. 
